\title{
Breastfeeding and neurological outcome at 42 months
}

\author{
CI Lanting ${ }^{1}, \mathrm{~S}$ Patandin ${ }^{2}, \mathrm{~N}$ Weisglas-Kuperus ${ }^{2}, \mathrm{BCL}$ Touwen $^{3}$ and ER Boersma ${ }^{1}$ \\ Department of Obstetrics/Paediatrics ${ }^{1}$, Perinatal Nutrition and Development Unit, University of Groningen, The Netherlands; \\ Department of Paediatrics ${ }^{2}$, Erasmus University and Hospital/Sophia Children's Hospital, Rotterdam, The Netherlands; \\ Department of Developmental Neurology ${ }^{3}$, University Hospital, Groningen, The Netherlands
}

\begin{abstract}
Lanting CI, Patandin S, Weisglas-Kuperus N, Touwen BCL, Boersma ER. Breastfeeding and neurological outcome at 42 months. Acta Pædiatr 1998; 87: 1224-9. Stockholm. ISSN 0803-5253

This study investigated the effect of early feeding mode on the neurological condition at 42 months. For this purpose, healthy pregnant women were recruited in Groningen and Rotterdam, The Netherlands. Children were healthy and born at term. At 42 months, the children were neurologically examined by means of the Touwen/Hempel technique. In addition to the clinical diagnosis, the neurological findings were interpreted in terms of optimality. Special attention was paid to the quality of movements in terms of fluency. In total, $200(51 \%)$ exclusively breastfed (for $\geq 6$ weeks) and 194 (49\%) formula-fed children were studied. Twelve (3\%) 42-month-old children were considered to be neurologically mildly abnormal and 1 child was diagnosed as abnormal. No effect of the type of feeding was found on the clinical diagnosis or the neurological optimality. After adjustments for study centre and social, obstetric, perinatal and neonatal neurological differences, a beneficial effect of breastfeeding on the fluency of movements was found (odds ratio for non-optimal fluency 0.56 ; $95 \%$ confidence interval $0.37-0.85$ ). The prolongation of full breastfeeding beyond 6 weeks did not influence the quality of movements. In conclusion, among Dutch preschool children, there was a small advantageous effect of full breastfeeding during the first 6 weeks of life on the fluency of movements. $\square$ Breastfeeding, child development, essential fatty acids, human milk, infant nutrition, neurological examination
\end{abstract}

CI Lanting, Department of Obstetrics and Gynaecology, Perinatal Nutrition and Development Unit, University Hospital Groningen, PO Box 30.001, 9700 RB Groningen, The Netherlands

Several studies have indicated a long-term beneficial effect of breastfeeding on psychomotor development (1-5), but little information is available on the effect of breastfeeding on neurological development. In two previous papers we investigated the effect of breastfeeding on postnatal neurological development in children born at term. First, neonatal and 9-y neurological follow-up data from a group of 135 breastfed and 391 formula-fed children born at term were studied (6). In the neonatal period, 53\% $(n=279)$ of these children either had a defined neurological syndrome or showed isolated signs of neurological deficit. The type of feeding during early life and the duration of breastfeeding were assessed in retrospect after a period of about $18 \mathrm{y}$. The data indicated a small beneficial effect of breastfeeding on long-term neurological development, but definite conclusions could not be drawn because of the retrospective design of the study.

Secondly, in a prospective longitudinal study neurological follow-up data were collected from a group of 418 children. The study was designed to examine the effects of environmental exposure to polychlorinated biphenyls (PCBs) and dioxins in breastmilk on child development. In contrast to human milk, formula milk is free of PCBs and dioxins, since animal fats have been replaced with fats of vegetable origin in the production process. Since we expected to find negative effects of these toxic compounds, the criteria for inclusion (see Methods) were strictly implemented in order to form an optimal study population in which the expected frequency of neurological abnormality is lower than that in the general population (7). Half of the women in the study breastfed their infant, while the other half formula-fed their child. In order to guarantee a substantial level of exposure, exclusive breastfeeding had to be sustained for at least 6 weeks. In addition to measures of prenatal and postnatal exposure to these contaminants, information was collected about the duration of lactation. The children were examined neurologically in their second week after birth, at 18 months of age and at 42 months. Although prenatal exposure to $\mathrm{PCBs}$ was negatively associated with the neurological condition at birth and at 18 months, no effect of lactational exposure to PCBs and dioxins on neurological development was found $(8,9)$. At 18 months of age, an advantageous effect of breastfeeding on the quality of movements in terms of fluency was found (8). The present study reports on the effect of early feeding type and the effect of the duration of exclusive breastfeeding on the neurological condition at 42 months in this cohort.

\section{Patients and methods}

The present study was initiated in June 1990. In two study centres (Groningen and Rotterdam, The Netherlands), 
pregnant women were asked to volunteer for participation. The women were asked to participate by their midwives or obstetricians in the 34th to 36th week of pregnancy. It was planned to form a study group consisting of 50\% breastfeeding mothers and $50 \%$ formula-feeding mothers. The women were provisionally assigned to one of two feeding groups on the basis of their intention to breastfeed or formula-feed their infant after birth. For inclusion in the study the mothers and their newborn infants had to meet the following criteria: (i) no serious illness or complications during pregnancy and delivery; (ii) a normal, spontaneous vaginal delivery; (iii) healthy, first or second born, term infants; and (iv) in order to rule out racial differences in neurological development, both parents had to be Caucasian. In addition, for assignment to the breastfeeding group, mothers had to sustain full lactation for at least 6 weeks after delivery. The number of weeks during which the child was fed exclusively on breastmilk was recorded. Formula-feeding mothers fed their infants exclusively on Almiron M2 from one batch (Nutricia NV, Zoetermeer, The Netherlands) for at least 6 months after birth. In the formula milk, PCB and dioxin levels have been found to be below the detection limit (8). The study protocol was approved by the medical ethics committees from the University Hospitals in both Groningen and Rotterdam.

\section{Neurological condition}

In the second week after birth, all neonates were examined neurologically using the technique designed by Prechtl (10). At 18 and 42 months, the children were re-examined using an age-specific neurological examination, the Touwen/Hempel technique (11). The neurological assessment is performed in a standardized free-field situation and focuses on the observation of motor functions (prehension, sitting, crawling, standing and walking). The 42-month-old children were classified as neurologically normal, mildly abnormal or abnormal. The clinical diagnosis "abnormal" means that the child suffers from an overt neurological syndrome, which usually leads to a handicap in daily life. The classification "mildly abnormal" implies that there are mild signs of neurological deficit which do not necessarily lead to a handicapping situation, such as signs of mild hypertonia or hypotonia, or slight asymmetries.

In addition to the clinical classification, the neurological findings were interpreted in terms of optimality (12). A list of 56 items was composed, for each of which an optimal range was defined (9). The neurological optimality score (NOS) was determined by counting the number of items falling within the optimal range. It should be kept in mind that optimality is not identical to "normal"; a reduced optimality score does not automatically imply a clinical diagnosis of "mildly abnormal" or "abnormal". However, mildly abnormal and abnormal children will virtually always show a reduced optimality score. Special attention was paid to the fluency of movements. For that purpose, a fluency cluster score was constructed for each 42-month-old child. The NOS contains 15 items describing the fluency of
Table 1. Items and criteria for optimality used to calculate the fluency cluster score at 42 months.

\begin{tabular}{ll}
\hline Item & Criteria for optimality \\
\hline $\begin{array}{l}\text { Prehension } \\
\text { 1. Quality of arm/shoulder movements }\end{array}$ & $\begin{array}{l}\text { Smooth } \\
\text { Absent or non-hindering } \\
\text { 2. Associated movements } \\
\text { 3. Quality of hand mobility }\end{array}$ \\
Sitting & Smooth \\
4. Trunk rotation, elicited & Trunk rotation $>45^{\circ}$ \\
5. Fluency of trunk movements & Smooth \\
6. Acceleration/deceleration & Smooth \\
Standing & \\
7. Trunk rotation, elicited & Trunk rotation $>45^{\circ}$ \\
8. Fluency of trunk movements & Smooth \\
9. Dyskinesia & No dyskinesia \\
Walking & \\
10. Ability to walk and toddle & \\
& Able to walk without help, \\
& and no toddling in the \\
11. Fluency of trunk movements & walking pattern at any speed \\
12. Fluency of leg movements & Smooth \\
13. Reciprocal arm swing & Present \\
14. Walking on tip-toe & No, or sometimes walking on \\
& tip-toe voluntarily \\
\hline
\end{tabular}

${ }^{\text {a }}$ The term toddling refers to the characteristic walking pattern of young children in which the trunk is moved block-like, and gait width is broad, and in which the legs appear to be moved like sticks.

movements during prehension, sitting, crawling, standing and walking (9). Re-inspection of the distribution of the 15 fluency items indicated a severe inconsistency in the appreciation of observations concerning the spontaneous trunk rotation during sitting between the two researchers. Therefore, this item was excluded, leaving 14 items which were used to calculate the fluency cluster score (Table 1).

\section{Explanatory variables}

Social, obstetric and perinatal conditions were extensively recorded using a 72-item questionnaire (13). For each mother/infant pair, the number of items that fulfilled preset optimality criteria (12) was counted, and used as an obstetric optimality score (13). The neurological condition at 42 months was assessed by two researchers, one in Groningen (CL) and one in Rotterdam (SP). Both examiners were trained and regularly supervised by BCLT. They were not informed about the early type of feeding, the duration of breastfeeding or the outcome of the neonatal and the 18-month neurological examinations.

\section{Data processing and statistics}

A regression analysis was performed to investigate the effect of the type of feeding and the duration of breastfeeding on the neurological condition at 42 months. The NOS and the fluency cluster score were the dependent variable. Considering the criteria for inclusion, it is not surprising that the distribution of the NOS was skewed to the left (Table 1). For statistical reasons, the NOS was normalized 
by logarithmic transformation into $-\ln (56.5-\mathrm{NOS})$ (the highest possible NOS is 56). The potential confounding factors were the neonatal neurological condition, the early type of feeding and the duration of full breastfeeding, and a selection from the 72 items from the obstetric optimality score \{i.e. the mother's age, body weight and height, body mass index [weight $(\mathrm{kg}) /$ height $(\mathrm{m})^{2}$ ], education, profession, and pregnancy cigarette and alcohol consumption, the partner's education and profession, and smoking habits at the time of pregnancy, and the infant's gestational age, gender, birth order and birthweight $\}$, the obstetric optimality score and the study centre. Parental education was categorized as follows: 0 , no qualifications; 1 , secondary education; and 2, university or higher professional training. Profession was coded 0 for skilled or unskilled workers, the unemployed or rejected, housewives and students, 1 for lower and middle-class employees, and 2 for independent middle-class and higher professionals. Other codings have been described elsewhere (13). The Student's $t$-test was used for the comparison of means, $\chi^{2}$-test for comparison of percentages, and Mann-Whitney $U$-test for comparison of non-parametric distributions. Results were judged significant when the $p$-value was $<0.05$.

\section{Results}

The intake of the breastfed and the formula-fed group was completed after a period of $2 \mathrm{y}$. At delivery, 489 mother/ infant pairs met the inclusion criteria, 71 (15\%) of which were lost, mainly due to difficulties in sustaining breastfeeding for 6 weeks or more, leaving a total number of 418 mother/infant pairs. For each mother the intention to breastfeed or formula-feed was equal to the actual feeding type. At 42 months the neurological examination was carried out in 394 (94\%) of these children. Thus, the final study population consisted of 394 42-month-old children. In $203(51 \%)$ of the cases the 42-month neurological examination was performed by CL (Groningen) and in 192 (49\%) cases by SP (Rotterdam). Two-hundred (51\%) of these children had been exclusively breastfed for at least 6 weeks as babies and 194 (49\%) had been formula-fed. This proportion of formula-feeding mother/infant pairs corresponds well with the expected prevalence on the basis of national data; in The Netherlands, $48 \%$ of mothers were found to formula-feed their infant (14). Table 2 shows the characteristics of the feeding groups. In the breastfeeding group the mean \pm SD maternal Quetelet index was 22 \pm 3 , indicating a good nutritional status. All mothers/infant pairs were regular visitors to an infant welfare centre.

\section{Clinical diagnosis vs feeding mode}

In the second week after birth, $94 \%$ of the study population was diagnosed as neurologically normal. The number of 42-month-olds diagnosed as "mildly abnormal" was somewhat higher in Rotterdam than in Groningen $[n=9$ $(5 \%)$ vs $n=3(1 \%)$, respectively; $p=0.06]$, although
Table 2. Characteristics of the feeding groups.

\begin{tabular}{|c|c|c|}
\hline Variable & Breastfed & Formula-fed \\
\hline Number of children & 200 & 194 \\
\hline $\begin{array}{l}\text { Study centre } \\
\text { Groningen } \\
\text { Rotterdam }\end{array}$ & $\begin{array}{r}103(51 \%) \\
97(49 \%)\end{array}$ & $\begin{array}{r}101(52 \%) \\
93(48 \%)\end{array}$ \\
\hline $\begin{array}{l}\text { Neonatal neurological diagnosis } \\
\text { Normal } \\
\text { Mildly abnormal } \\
\text { Abnormal }\end{array}$ & $\begin{aligned} & 188(94 \%) \\
& 10(5 \%) \\
& 2(1 \%)\end{aligned}$ & $\begin{aligned} 182 & (94 \%) \\
10 & (5 \%) \\
2 & (1 \%)\end{aligned}$ \\
\hline $\begin{array}{l}\text { Neurological optimality score at } 42 \text { months } \\
\text { 25th, 50th, 75th percentile }\end{array}$ & $51,52,54$ & $50,52,53 *$ \\
\hline $\begin{array}{l}\text { Obstetric optimality score } \\
25 \text { th, } 50 \text { th, } 75 \text { th percentile }\end{array}$ & $63,65,66$ & $61,64,66^{*}$ \\
\hline $\begin{array}{l}\text { Maternal age }(y) \\
\text { mean } \pm S D\end{array}$ & $30 \pm 3$ & $28 \pm 4^{*}$ \\
\hline $\begin{array}{l}\text { Maternal weight }(\mathrm{kg}) \\
\text { mean } \pm \mathrm{SD}\end{array}$ & $64 \pm 9$ & $66 \pm 11$ \\
\hline $\begin{array}{l}\text { Quetelet index }\left(\mathrm{kg} \mathrm{m}^{-2}\right) \\
\text { mean } \pm \mathrm{SD}\end{array}$ & $22 \pm 3$ & $23 \pm 4$ \\
\hline $\begin{array}{l}\text { Smoking during pregnancy } \\
\text { Mother, yes } \\
\text { Father, yes }\end{array}$ & $\begin{array}{l}33(17 \%) \\
78(39 \%)\end{array}$ & $\begin{array}{l}69(36 \%)^{*} \\
86(44 \%)\end{array}$ \\
\hline No alcohol consumption during pregnancy & $127(63 \%)$ & $158(81 \%)^{*}$ \\
\hline $\begin{array}{l}\text { Formal education } \\
\text { Mother, high }^{\mathrm{a}} \\
\text { Father, high }^{\mathrm{a}}\end{array}$ & $\begin{array}{l}126(63 \%) \\
125(62 \%)\end{array}$ & $\begin{array}{l}48(25 \%)^{*} \\
64(33 \%)^{*}\end{array}$ \\
\hline $\begin{array}{l}\text { Profession } \\
\text { Mother, high } \\
\text { Father, high }^{\mathrm{b}}\end{array}$ & $\begin{array}{r}83(41 \%) \\
117(56 \%)\end{array}$ & $\begin{array}{l}27(14 \%)^{*} \\
62(32 \%)^{*}\end{array}$ \\
\hline $\begin{array}{r}\text { Gender } \\
\text { Male }\end{array}$ & $114(57 \%)$ & $99(51 \%)$ \\
\hline $\begin{array}{l}\text { Birth order } \\
\text { Firstborn }\end{array}$ & $107(53 \%)$ & $86(44 \%)$ \\
\hline $\begin{array}{l}\text { Birthweight }(\mathrm{kg}) \\
\text { mean } \pm \mathrm{SD}\end{array}$ & $3.54 \pm 0.46$ & $3.49 \pm 0.43$ \\
\hline $\begin{array}{l}\text { Duration of exclusive breastfeeding (weeks) } \\
25 \text { th, 50th, } 75 \text { th percentile }\end{array}$ & $9,13,22$ & 0 \\
\hline
\end{tabular}

${ }^{\mathrm{a}}$ Higher secondary, professional, or university training; ${ }^{\mathrm{b}}$ independent middle-class or higher profession.

*Significantly different from breastfed group $(p<0.05)$.

statistical significance was not reached. Four of the 12 42-month-olds classified as "mildly abnormal" were in the breastfed group, whereas 8 were in the formula-fed group. One child, who had been breastfed as a baby, was considered to be neurologically "abnormal" and showed signs of spastic diplegia. The remaining 381 (97\%) children were considered to be neurologically "normal". Of the 42-month-olds classified as "normal", 195 (51\%) were in the breastfed group and 186 (49\%) were in the formulafed group. After adjustment for confounding variables, the type of feeding proved to be unrelated to the clinical diagnosis.

\section{NOS vs feeding mode}

In Groningen, the median NOS at 42 months was equal to 
53 (range 47-56). In Rotterdam, the median NOS proved to be 51 (range 30-56). This difference between the two observers was found to be significant $(p<0.01)$ and was mainly due to a systematic difference in the assessment of the following 10 items: yoke movements, spontaneous trunk rotation, fluency of trunk movements, posture during standing, distance between feet, ability to walk and toddle, posture during walking, manoeuvrability during walking, position of the eyes and reflex thresholds. In the neurologically "normal" group, the median (range) NOS was 52 (37-56), whereas among the neurologically "mildly abnormal" or "abnormal" children the median (range) NOS equalled $38(30-53)(p<0.001)$. The NOS was significantly higher in the breastfed group than in the formula-fed group $(p=0.04)$. However, after adjusting for confounding factors in a linear regression analysis, the early type of feeding was no longer associated with the NOS at 42 months. The duration of full breastfeeding was also unrelated to the NOS at 42 months.

\section{Fluency of movements vs feeding mode}

In both Groningen and Rotterdam, the median fluency cluster score equalled 13. In Groningen the fluency cluster score ranged from 9 to 14 and in Rotterdam it ranged from 5 to $14(p=0.02)$. This difference is mainly caused by a systematic interobserver difference in the assessment of the following items: elicited trunk rotation, and ability to walk and toddle. Considering the distributions of the fluency cluster score for breastfed and formula-fed children (Fig. 1), it was decided for methodological reasons to dichotomize the fluency cluster score at the median of the pooled data. A fluency cluster score equal to 14 was considered to be optimal, whereas a fluency cluster score of 13 or less was considered to be non-optimal. In $52 \%(n=104)$ of the breastfed 42-month-old children the fluency cluster score

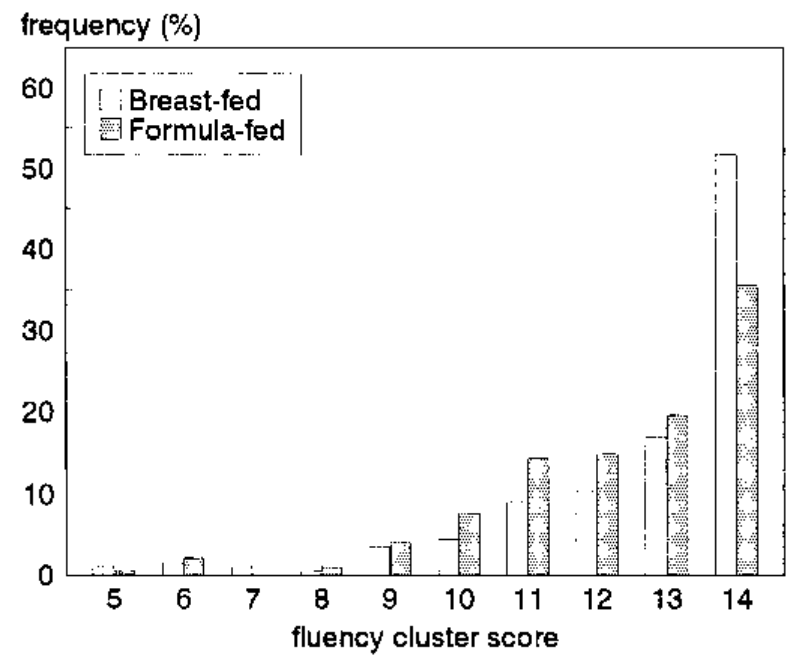

Fig. 1. Distribution of the fluency cluster score at 42 months of age according to type of infant feeding.
Table 3. Results of a logistic regression analysis on a non-optimal fluency cluster score. ${ }^{\mathrm{a}}$

\begin{tabular}{lcc}
\hline Variables & Odds ratio & $\begin{array}{c}95 \% \text { confidence } \\
\text { interval }\end{array}$ \\
\hline $\begin{array}{l}\text { Feeding group } \\
\text { Formula-feeding vs breastfeeding }\end{array}$ & 0.56 & $0.37-0.85$ \\
$\begin{array}{l}\text { Maternal smoking during pregnancy } \\
\text { No vs yes }\end{array}$ & 1.62 & $1.01-2.64$ \\
$\begin{array}{l}\text { Study centre } \\
\text { Groningen vs Rotterdam }\end{array}$ & 1.06 & $0.71-1.59$ \\
\hline
\end{tabular}

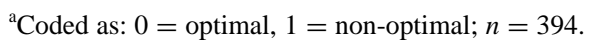

was considered to be optimal, whereas among the formulafed toddlers this was $35 \%(n=69)(p<0.01)$. In a logistic regression analysis, a significant association with the type of feeding was found (Table 3 ). In addition to the feeding type, smoking by the mother during pregnancy and the study centre were included in the final model. Other explanatory variables did not improve the model fit and did not explain the effect of feeding type. The fluency cluster score was found to be unrelated to the duration of exclusive breastfeeding.

\section{Discussion}

In the group of 42-month-olds who were fed formula milk during the first 6 months of life, the frequency of a nonoptimal fluency of movements was about twice as high as that found among toddlers who were fully breastfed for 6 weeks or more. This beneficial effect of breastfeeding was also found at 18 months of age in the present cohort (8). The fluency of movements has been found to be a reflection of brain integrity in fetuses and preterms $(15,16)$. Recently, it was reported that an abnormal quality of movements during fetal life and early infancy is a marker of later neurological dysfunction (17). Whether the presence and severity of non-fluency of movements is associated with behavioural and cognitive problems at later ages remains to be investigated. Such an association has been found for mild neurological dysfunction at $9 \mathrm{y}$ of age (18).

The advantageous effect of breastfeeding on the quality of movements was found in a low-risk population for neurological abnormality (see inclusion criteria). This cohort was examined neurologically by two researchers, one in Rotterdam and one in Groningen. Both NOS and fluency cluster score differed significantly between the two study centres, being systematically higher in Groningen than in Rotterdam. In order to account for these differences, adjustments were made for the study centre.

Breastfeeding avoids many of the hazards of artificial feeding, including infection (19) and malnutrition in developing countries, and allergic disorders $(19,20)$ and obesity (21) in more developed societies, and is generally recognized as the most optimal method of infant feeding (22). In Western countries research on the developmental effects of 
breastfeeding is complicated by the fact that breastfed children tend to come from more advantaged home environments than their formula-fed counterparts. The educational and professional level of both parents was higher in the breastfeeding group than in the formula-feeding group. Also, breastfeeding mothers were older, they were more likely to be non-smokers, and they more often consumed alcohol during pregnancy than the formula-feeding mothers (Table 2). In the present study social, obstetric and perinatal factors had no effect on the quality of movements. Adjustments were made for the study centre and maternal smoking during pregnancy. However, it cannot be completely excluded that the advantageous effect of breastfeeding is caused by factors such as genetic potential, or parental lifestyle and health attitudes.

Three mechanisms could account for the beneficial effect of breastfeeding: (i) the psychosocial aspect of nursing may play a role; (ii) it is known that maternal hormones (e.g. thyroid hormone and thyroid-stimulating hormone) and other biologically active peptides are transferred to the infant via breastmilk (23), and may influence brain (24) and muscle development; and (iii) components of breastmilk may be responsible. Besides differences in, for example, monosaccharides and sugar alcohols (25), breastmilk and formula milk differ considerably in lipid composition. In contrast to most term formula milks, breastmilk contains various long-chain polyunsaturated fatty acids (LCPUFAs) (25). LCPUFAs, and especially docosahexaenoic (DHA) and arachidonic acids (AA), are considered to be essential nutrients during fetal life and early infancy, and they make up a major part of the structural lipids in brain and nervous tissue (26). Owing to a low capacity of the enzymes required for the synthesis of AA and DHA from their precursors (linoleic and $\alpha$-linolenic acid, respectively), breastmilk is virtually the sole source of these fatty acids in the first weeks of life. Supplementation of preterm infants with DHA has been found to improve visual as well as cognitive function $(27,28)$. In term infants, Agostoni et al. (29) found a higher developmental quotient in infants who received formula supplemented with LCPUFAs than in infants fed on a standard formula. Assuming that the beneficial effect on brain function is related to these components of human milk, the absence of an effect of the duration of full breastfeeding (for $\geq 6$ weeks) suggests that breastfeeding exerts its advantageous effect in the first weeks of life. This hypotheses is supported by our previous finding that full breastfeeding for 3 weeks or more has a positive effect on neurological development, whereas no effect was found of shorter periods of breastfeeding (6). Others also found a beneficial influence of short courses of breastfeeding on neurodevelopment $(5,30)$.

The difference between the two feeding groups with respect to neurological development is small. This was also the case in studies concerning cognitive development (1-4). Considering the fact that both feeding groups are at low risk for developmental disturbances (a low risk which is reflected by the small number of clinically not quite normal children), the finding that the type of feeding influences the quality of motor behaviour within a group of normally developing children is remarkable. This small effect should not alarm individual mothers who for a good reason do not breastfeed their infant. However, it should be remembered that on a population basis such a minor increase in the mean score may have a noticeable effect.

In conclusion, in 42-month-old children a small beneficial effect of full breastfeeding during the first 6 weeks of life on the quality of movements in terms of fluency was found. The prolongation of full breastfeeding beyond 6 weeks did not influence the neurological condition at 42 months.

Acknowledgments. - The Dutch PCB/dioxin Breast milk Study is funded by the European Community (contract no. EV5V-CT92-0207). We thank Dr M. Huisman and Dr C. Koopman-Esseboom for the recruitment of the mothers.

\section{References}

1. Ferguson DM, Beautrais AL, Silva PA. Breast-feeding and cognitive development in the first seven years of life. Soc Sci Med 1982; 16: 1705-8

2. Morrow-Tlucak M, Haude RH, Ernhart CB. Breast-feeding and cognitive development in the first 2 years of life. Soc Sci Med 1988; 26: 635-9

3. Lucas A, Morley R, Cole TJ, Lister G, Leeson-Payne C. Breast milk and subsequent intelligence quotient in children born preterm. Lancet 1992; 339: 261-4

4. Rogan WJ, Gladen BC. Breast-feeding and cognitive development. Early Hum Dev 1993; 31: 181-93

5. Florey $\mathrm{C}$ du V, Leech AM, Blackhall A. Infant feeding and motor development at 18 months of age in first born singletons. Int $\mathrm{J}$ Epidemiol 1995; 24 Suppl 1: 21-6

6. Lanting CI, Fidler V, Huisman M, Touwen BCL, Boersma ER. Neurological differences between 9-year-old children fed breastmilk or formula-milk as babies. Lancet 1994; 344: 1319-22

7. Huisman M, Koopman-Esseboom C, Fidler V, Hadders-Algra M, Paauw CG van der, Tuinstra LGMTh, et al. Perinatal exposure to polychlorinated and dioxins and its effect on neonatal neurological development. Early Hum Dev 1995; 41: 111-27

8. Huisman M, Koopman-Esseboom C, Lanting CI, Paauw CG van der, Tuinstra LGMTh, Fidler V, et al. Neurological condition in 18month-old children perinatally exposed to polychlorinated biphenyls and dioxins. Early Hum Dev 1995; 43: 165-76

9. Lanting CI, Patandin S, Fidler V, Weisglas-Kuperus N, Sauer PJJ, Boersma ER, Touwen BCL. Neurological condition in 42-month-old children in relation to pre- and postnatal exposure to polychlorinated biphenyls and dioxins. Early Hum Dev 1998; 50: 283-92

10. Prechtl HFR. The neurological examination of the full-term newborn infant. 2nd ed. Clinics in Developmental Medicine, No. 63. SIMP. London: Heinemann Medical Books, 1977

11. Hempel MS. The neurological examination for toddler-age (Dissertation). Groningen: University of Groningen, 1993

12. Prechtl HFR. The optimality concept. Early Hum Dev 1980; 4: 201-5

13. Touwen BCL, Huisjes HJ, Jurgens-van der Zee AD, Bierman-van Eendenburg MEC, Smrkovsky M, Olinga AA. Obstetrical condition and neonatal neurological morbidity. An analysis with help of the optimality concept. Early Hum Dev 1980; 4: 207-28

14. Burgmeijer RJF. Groei van borstgevoede kinderen. In: Wit JM, editor. De vierde landelijke groeistudie (1997). Leiden: University of Leiden, Boerhave Committee, 1998: 37-53 (in Dutch)

15. Ferrari F, Cioni G, Prechtl HFR. Qualitative changes of general movements in preterm infants with brain lesions. Early Hum Dev 1990; 23: 193-231 
16. Prechtl HFR. Qualitative changes of spontaneous movements in fetus and preterm infant are a marker of neurological dysfunction. Early Hum Dev 1990; 23: 151-8

17. Prechtl HFR, Einspieler C, Cioni G, Bos AF, Ferrari F, Sontheimer D. An early marker for neurological deficits after perinatal brain lesions. Lancet 1997; 349: 1361-3

18. Hadders-Algra M, Huisjes HJ, Touwen BCL. Perinatal risk factors and minor neurological dysfunction: significance for behaviour and school achievement at nine years. Dev Med Child Neurol 1988; 30: 472-81

19. Chandra RK. Prospective studies of the effect of breast feeding on incidence of infection and allergy. Acta Paediatr Scand 1979; 68: 691-4

20. Saarinen UM, Kajosaari M. Breast-feeding as prophylaxis against atopic disease: prospective follow-up study until 17 years old. Lancet 1995; 346: 1065-9

21. Kramer MS. Do breast-feeding and delayed introduction of solid foods protect against subsequent obesity? J Pediatr 1981; 98: 883-7

22. Espgan Commitee on Nutrition. Guidelines on infant nutrition III. Recommendations for infant feeding. Acta Paediatr Scand 1987; Suppl 302: 3-27

23. Koldovsky O. Hormones in human milk. In: Lebenthal E, editor Textbook of gastroenterology and nutrition in infancy. New York: Raven Press, 1989

24. Lucas A, Morley R, Fewtrell MS. Low triiodothyronine concentration in preterm infants and subsequent intelligence quotient (IQ) at 8 year follow up. BMJ 1996; 312: 1132-3

25. Huisman M, van Beusekom CM, Lanting CI, Nijboer HJ, Muskiet FAJ, Boersma ER. Triglycerides, fatty acids, sterols, mono- and disaccharides, and sugar alcohols in human milk and current types of infant formula milk. Eur J Clin Nutr 1996; 50: 255-60

26. Farquharson J, Cockburn F, Ainslie Patrick W, Jamieson EC, Logan RW. Infant cerebral cortex phospholipid fatty-acid composition and diet. Lancet 1992; 340: 810-3

27. Birch DG, Birch EE, Hoffman DR, Uauy R. Dietary essential fatty acid supply and visual acuity development. Invest Ophthalmol Vis Sci 1992; 33: 3242-53

28. Woltil A. Early nutrition of low birtweight infants: LCPUFA metabolism, growth and development (Dissertation). Groningen: University of Groningen, 1997

29. Agostoni C, Trojan S, Bellu R, Riva E, Giovanni M. Neurodevelopmental quotient of healthy term infants at 4 months and feeding practice: the role of long-chain polyunsaturated fatty acids. Pediatr Res 1995; 38: 262-6

30. Riva E, Agostoni C, Biasucci G, Trojan S, Luotti D, Fiori L, Giovanni M. Early breast-feeding is linked to higher intelligence quotient scores in dietary treated phenylketonuric children. Acta Paediatr 1996; 85: 56-8

Received Mar. 28, 1998. Accepted in revised form Aug. 25, 1998 